\title{
Prospect Analysis for the Complementary Development of Gas-Fueled and Electric Vehicles in China
}

\author{
Xue-Hang BIAN ${ }^{1, a}$, Jie GUO ${ }^{1, b,{ }^{*}}$,Bin OUYANG ${ }^{1}$, Yi ZHANG $^{1}$ and Zhen-Hua \\ FENG $^{1}$
}

\author{
(1. China Academy of Transportation Sciences, Beijing 100029, China) \\ a289418895@qq.com, b61044812@qq.com
}

\begin{abstract}
Keywords: gas-fueled vehicle; electric vehicle; clean energy application; new energy application
\end{abstract}
\begin{abstract}
In order to analyze in detail the prospective development of gas-fueled vehicles and electric vehicles. Based on a wealth of data and extensive research, the development scale, growth rate and policy support for gas-fueled and electric vehicles are elaborated, and the development status and characteristics are summarized herein. The main problems with gas-fueled and electric vehicles, at present and respective advantages during popularization will be described respectively. On this basis, forecast and analysis will be made on the prospective development of gas-fueled and electric vehicles. It is concluded that gas-fueled and electric vehicles will be developed in different models, regions and fields in the foreseeable future. Therefore, this paper could provide important data as well as a technical reference for the development of clean energy in the auto industry.
\end{abstract}

\section{Introduction}

In 2016, vehicle ownership in China reached 0.194 billion [1]. Compared with data from 2011, it had increased by $83 \%$, growing at an average annual rate of $12.85 \%$. With the rapid popularization of cars, there were many problems such as substantial growth of energy consumption, atmospheric pollution, carbon emission and so on. Therefore, it is particularly urgent to improve methods for energy consumption. It was stated in the Report on the Work of the Government in 2017: "to encourage use of clean-energy vehicles", it thereby indicated the government policy to actively promote the use of clean energy vehicles such as gas-fueled and electric vehicles. This important measure will guarantee the security of the country's energy, will enhance the prevention and control of air pollution and deal with climate change issues. According to country's policy guidance and future market demand, this paper will sort through and analyze the current situation and characteristics of gas-fueled and electric vehicles in recent years, and complete a research analysis on the prospect for complementary development of gas-fueled and electric vehicles.

\section{Current Situation and Characteristics of Gas-Fueled Vehicles}

\section{Current Situation of Gas-Fueled Vehicles}

From 2010 to 2015, the Chinese government promulgated a package of supportive policies to popularize the application of gas-fueled vehicles. In October 2012, Policies on the Utilization of Natural Gas was issued by the National Development and Reform Commission (NDRC), classifying development of gas-fueled vehicles as a priority industry. Many important documents successively issued by the Ministry of Transport of the People's Republic of China, for example, the $12^{\text {th }}$ Five-Year Plan of Transport, the $12^{\text {th }}$ Five-Year Plan on Energy Conservation and Emission Reduction for Highway Transportation and Water Transportation, Guidance on Establishment of Low Carbon Transport System and Guidance on Accelerating Development of Green, Recyclable and Low Carbon Transportation, have clearly put forward the necessity to speed up the application of alternative energy sources. Development of gas-fueled vehicle in our country have the following characteristics:

I. Continuous and explosive growth of gas-fueled vehicle ownership, followed by a sudden drop in growth rate in the past two years. In recent years, application of gas-fueled vehicles in 
our country has entered a stage of explosive growth. In 2011, gas-fueled vehicle ownership of China reached 1.523 million and it reached up to 5.03 million by 2015[2] with an average annual growth rate of $46 \%$. Thus, China ranks first in the world with the largest gas-fueled vehicle ownership. However, when the growth rate of gas-fueled vehicle ownership reached a peak of $56 \%$ in 2013 , it dropped to 37\% in 2014 and 9\% in 2015, as shown in Figure 1. This was influenced by many factors such as policy guidance changes and market price fluctuation of oil and gas.

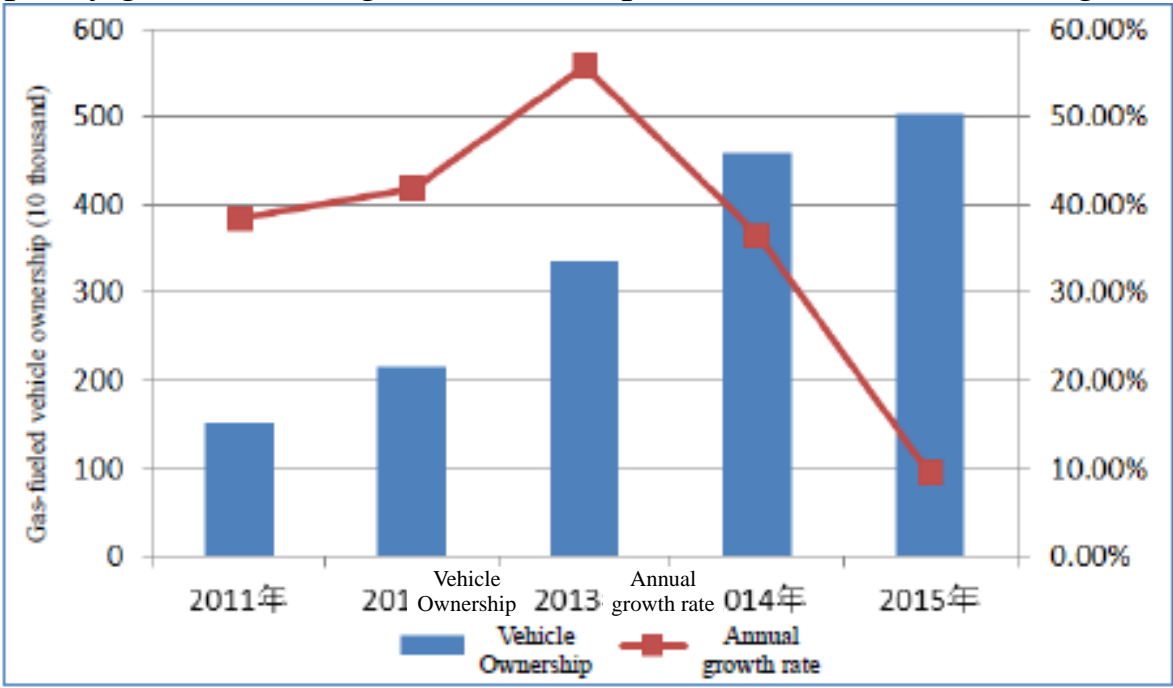

Figure 1 Changes in the ownership of gas-fueled vehicles in recent years

II. Biggest ownership of natural gas passenger vehicles; Liquefied Natural Gas (LNG) vehicles are mainly Heavy Goods Vehicles (HGVs) and buses. Judging from the structure of gas-fueled vehicles in 2015, as shown in Figure 2, the ratio of natural gas (including dual fuel) passenger vehicles reached $74 \%$, occupying the majority, including a considerable amount of taxis and private cars with "oil to gas" modifications. LNG vehicles were mainly used as commercial vehicles. The ratio of HGVs reached $65 \%$ while that of passenger vehicles reached $25 \%$ amongst all pure LNG vehicles.
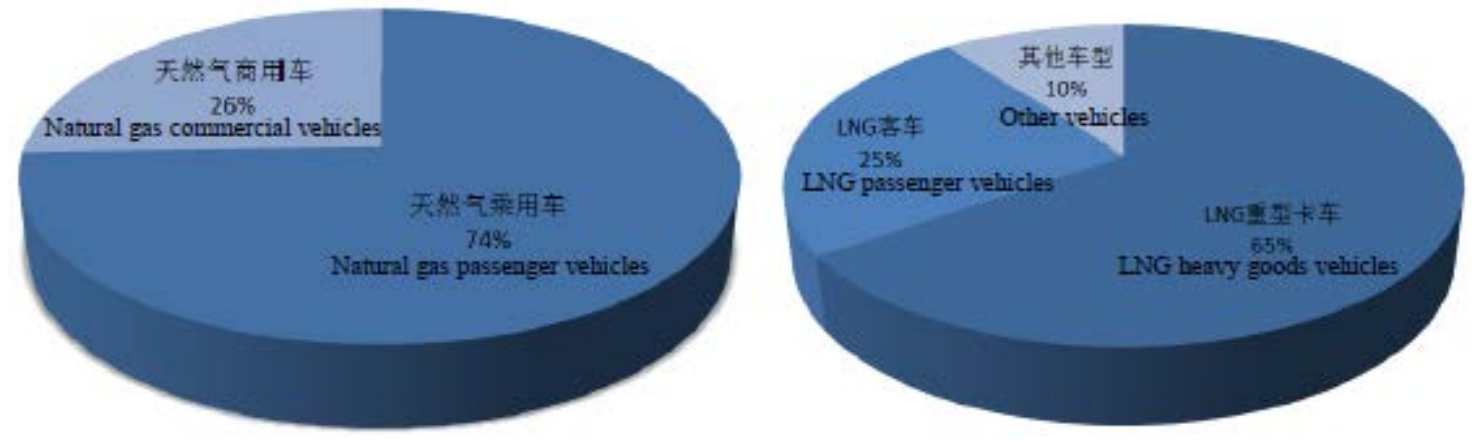

Figure 2 Structure of gas-fueled vehicles

III. Prompt popularization of vehicles running on natural gas under policy and financial support. Since 2012, special funds for transportation energy conservation and emissions reduction established by the Ministry of Transport and the Ministry of Finance have supported a large number of application programs for natural gas vans and dual fuel taxies. The ratio of assistance funding supporting natural gas-fueled vehicles reached over $28 \%$ and for natural gas-fueled vehicles, including natural gas passenger cars, trucks and dual fuel taxies, the assistance funding is still increasing year by year, promoting the use of natural gas-fueled vehicles. As shown in Table 1: 
Table 1 Growth situation of vehicles running on natural gas

\begin{tabular}{|l|c|c|c|c|}
\hline Year & 2010 & 2013 & 2015 & $\begin{array}{l}\text { Total growth } \\
\text { rate }\end{array}$ \\
\hline $\begin{array}{l}\text { Total amount of vehicles running on } \\
\text { natural gas (10 thousand) }\end{array}$ & 38 & 97 & 115.5 & 204 \\
\hline Natural gas buses (10 thousand) & 6.99 & 16.1 & 20 & 186.1 \\
\hline Natural gas taxies (10 thousand) & 25.1 & 62.3 & 64.5 & 157 \\
\hline $\begin{array}{l}\text { Natural gas passenger cars (10 } \\
\text { thousand) }\end{array}$ & 1.78 & 4.1 & 6 & 237.1 \\
\hline Natural gas trucks (10 thousand) & 3.07 & 11.7 & 17 & 453.8 \\
\hline $\begin{array}{l}\text { Other gas-fueled vehicles (10 } \\
\text { thousand) }\end{array}$ & 1.06 & 2.77 & 8 & 654.7 \\
\hline
\end{tabular}

\section{Confronting Problems during Popularization of Gas-Fueled Vehicles}

There are several important reasons for the sudden drop in the growth rate of gas-fueled vehicle popularization since 2014:

I. A drop in oil prices resulted in a loss of cost advantage for gas-fueled vehicles. Oil prices began to slump in the summer of 2014. And the natural gas prices as a whole were expected to increase. This brought down the cost advantage of a gas-fueled vehicle.

II. The country's policy guidance changes lead to a a significant market share being transferred from gas-fueled vehicles to electric vehicles. Since 2014, the new energy vehicles received growth momentum, benefiting from a large amount of national subsidies for electric vehicles and a series of supporting policies. The production of electric vehicles (including blade electric vehicles and plug-in hybrid electric vehicles) surged from 17.4 thousand in 2013 to 379 thousand in 2015, occupying some of the market share previously held by gas-fueled vehicles.

III. Insufficient gas stations and other supporting facilities limited the development of gas-fueled vehicles. Corresponding gas stations and supporting pipeline networks are required for the popularization and application of gas-fueled vehicles in cities, which involves many factors such as urban planning and investment. The high cost of gas station installation, long inspection and approval periods, as well as insufficient supporting gas stations, all limited the development of gas-fueled vehicles.

\section{Advantages for the Popularization of Gas-Fueled Vehicles in Our Country}

Although the growth rate in ownership of natural gas vehicles decreases due to many factors, there is, however, still a good basis and many advantages for promoting the application of gas-fueled vehicles in our country.

I. There are huge application potentials for gas-fueled vehicles in the future. The current gas-fueled vehicle ownership is less than $3 \%$ of the total vehicle ownership in our country (including the vast number of dual-fuel vehicles). Also, natural gas consumption is far less than 3\% of total national energy consumption. It was pointed out in $13^{\text {th }}$ Five-Year Plan of Energy Development that the consumption ratio of natural gas should reach at least $10 \%$ by 2020 . Therefore, there are still huge application popularization potentials for gas-fueled vehicles.

II. There are abundant reserves of natural gas resources in our country. The natural gas resources in our country are abundant [3]. The proven gas reserves reach 3.8 trillion cubic meters. Every year, 12 billion cubic meters of natural gas can be transmitted through the west-east national gas transmission project to the Yangtze River delta and areas along it. Natural gas pipeline networks are improving gradually. The development and utilization of natural gas is a supplement to the shortage of oil resources and it also lowers foreign dependence.

III. Technology of gas-fueled vehicles is becoming more sophisticated. In China, the relevant technologies for gas-fueled vehicles are still developing and becoming increasingly sophisticated[4]. At present, China can domestically manufacture new types of engines, cylinders, and domestically 
install gas station devices such as compressors, gas storage devices and decontamination equipment. The range and reliability of the technology is also improving gradually.

\section{Current Situation and Characteristics of New Energy Vehicles \\ Current Situation of New Energy Vehicles}

Strategies for new energy vehicles were first proposed by the State Council through automobile industry revitalization planning as early as Jan. 14, 2009. After 2012, Planning for the Development of the Energy-Saving and New Energy Automobile Industry (2012-2020), Plan for the Development of Strategic Emerging Industries of the State in the $12^{\text {th }}$ Five-Year, Guidance on Accelerating Application Popularization of New Energy Vehicles and other planning and policy documents were successively issued and printed by the State Council. In March 2015, Implementation Suggestions on Accelerating Application Popularization of New Energy Vehicles in Transportation Industry issued by the Ministry of Transport of the People's Republic of China, clearly put forward development goals and specific tasks for new energy vehicles and their supporting facilities.

Following the appearance of these policies, the new energy vehicle industry has entered a high-speed development period in China. For the past few years, the development of new energy vehicles in our country have had the following characteristics:

I. There was a big leap in production and sales of new energy vehicles and the market application popularization developed significantly. In 2010 , the early phase of the " $12^{\text {th }}$ five-year plan”, the production volume of new energy vehicles was 6313 while sales volume was 6273 . But in a later period of " $12^{\text {th }}$ five-year plan", there was a big leap in production and sales of new energy vehicles. In 2015, the production volume reached 340471 while sales volume was 331092[5]. Compared with data from 2014, they increased respectively by 333\% and 342\%.

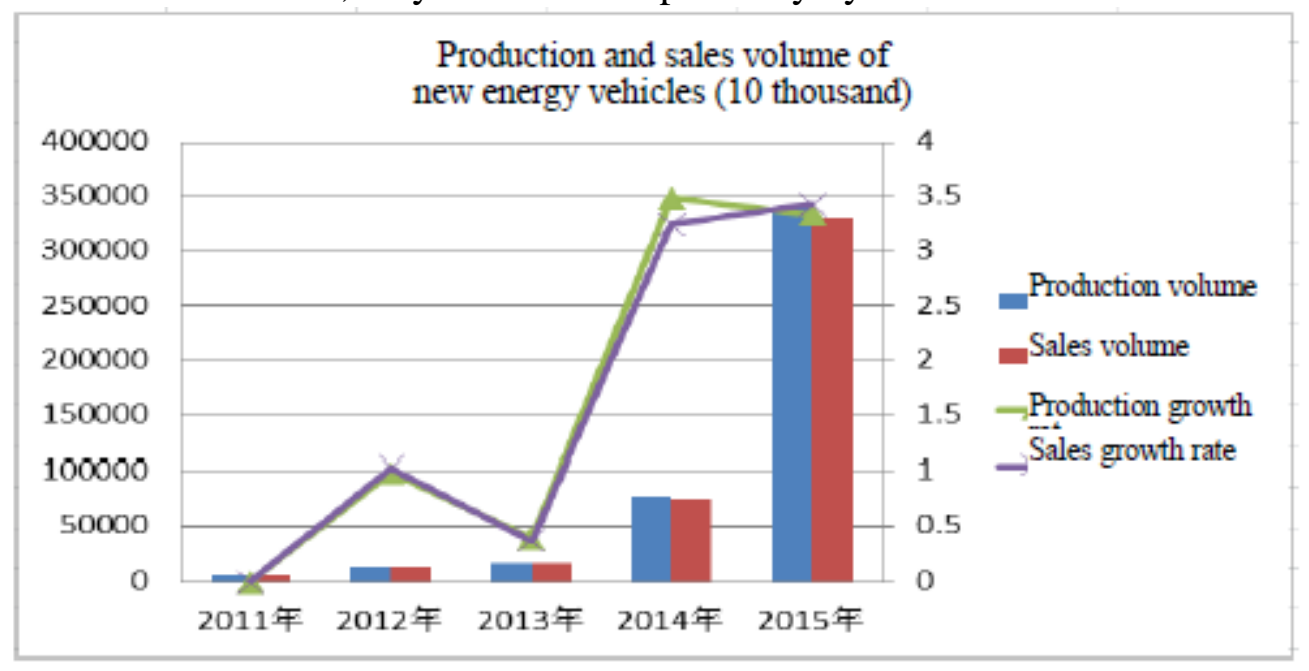

Figure 3 Production and sales of new energy vehicles in the past five years

II. Demand for passenger cars is the biggest among all new energy vehicles and the blade electric vehicle is the best selling model. Judging from the structure of new energy vehicles production and sales, the passenger cars ratio is the biggest among all new energy vehicles. In 2015, the sales volume of new energy passenger cars reached 207.4, accounting for $62.6 \%$ of total sales, which indicated passenger cars was still the main application of new energy vehicles. In 2015, the production volume of blade electric vehicles was 254633 while sales volume was 24782, accounting for $74.8 \%$ and $74.7 \%$ respectively, occupying the market majority.

III. Private car, car rental and bus fields have become the biggest user groups of new energy vehicles. Up to the end of December, 2015, the proportion of new energy vehicle usage for private cars was 35\%, while it was $20 \%$ for car rental and $17 \%$ for bus fields. These three fields accounted for the biggest ratio of application popularization for new energy vehicles [6]. It also indicated that following the development of new energy technology, supporting facilities and relevant subsidy 
policies, more people purchased new energy vehicles as private cars. At the same time, local governments increased the investment on new energy vehicles in the public transport industry, taking advantage of opportunities provided with the policies. Also, due to its energy-saving and environmental characteristics as well as policy advantages, electric vehicles are more likely to be adopted in the car rental industry.

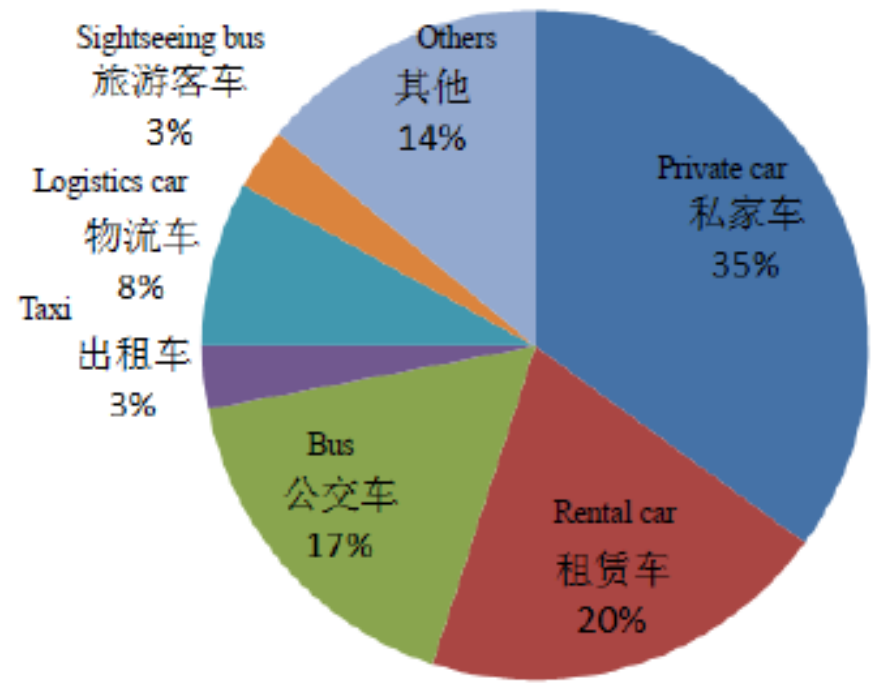

Figure 4 Structure of new energy vehicles

\section{Confronting Problems during Popularization of Electric Vehicles}

Although under the support of policies the use of electric vehicles have been popularized rapidly in the past two years, the application popularization has still been restricted by the following factors:

I. Short range and small load capabilities of electric vehicles. The technologies of electric vehicle power batteries and motors are still developing. Also, the low energy density of power battery [7], relatively short range and small load capabilities are not suitable for heavy goods vehicles and intercity coaches.

II. High price and short battery life of electric vehicles. The high price of batteries used by electric vehicles contributes to the high price of the vehicles themselves. So compared with petroleum fueled vehicles, the cost-performance ratio is much lower. In addition, the battery life is relatively short. So there are no price advantages without subsidies.

III. Insufficient supporting facilities like charging points limit the development of electric vehicles.

\section{Advantages for Application Popularization of Electric Vehicles}

I. Policy support. Since 2014, many favorable measures have been taken by the Chinese government through fiscal subsidies, tax exemption policies, no limitation policies for the manufacture and application of new energy vehicles. Both state government and local governments have clearly expressed from the aspect of strategy, planning and policy to develop new energy vehicles, focusing mainly on electric vehicles.

II. No pollution. Low noise. Application popularization of electric vehicles can effectively alleviate air pollution and reduce noise pollution in cities.

III. Simple structure and easier maintenance at later periods. For electric vehicles, the electromotor is used as a generator with a simple structure, making it easier to maintain at later periods.

IV. It would be a great opportunity to "overtake" non-domestic competitors in the auto technology industry, and to take control of the core technology and the market by promoting the application of electric vehicles. It would be a good opportunity to take control of the core technology and drive the development of the auto industry if new electric vehicle technology is developed. 


\section{Prospect for Complementary Development of Gas-Fueled Vehicle and Electric Vehicle}

There are certain differences between gas-fueled and electric vehicles in aspects like technology maturity level, fuel type, dynamic performance and so on. As clean energy vehicles, gas-fueled and electric vehicles both have huge potential for development in the future. The complementary application and development of both types of vehicles in different regions and fields should be popularized, combining characteristics and current technology as well as the basic conditions of gas-fueled and electric vehicles.

I. Leap forward the popularization and application of electric vehicles in the passenger car and city bus fields. The sales market of new energy vehicles in 2015 reflected changes in consumer buying trends. The simple structure and convenient maintenance of electric vehicles, along with key progress in the battery technology of new energy vehicles, as well as the setup of charging station networks in cities, will further stimulate the consumer demands on private and shared electric vehicles. Electric vehicles will be rapidly popularized in the passenger car field, such as private and "rental" cars; and the low pollution and low noise characteristics of electric vehicles will be suitable for the popularization and application in the urban transport field. Compared with gas stations, the establishment of charging points has a smaller influence on urban planning and requires less land, therefore, it is more suitable for the popularization in the urban bus field. In 2015, Implementation Suggestions on Accelerating Application Popularization of New Energy Vehicles in Transportation Industry issued by the Ministry of Transport of the People's Republic of China, clearly put forward that the number of new energy buses shall reach 200,000 by 2020. It was also clearly stated in Notice on Perfecting Price Subsidy Policy of Petroleum for Urban Buses and Accelerating Application Popularization of New Energy Vehicles issued by the Ministry of Finance that increases in the subsidy amount for petroleum price rises will be influenced by the popularization quantity of new energy buses and that operating subsidies will be distributed for new energy buses. These policies will introduce a huge increase in urban bus demand, accelerating application and popularization of new energy vehicles in the urban public transport field.

II. Gas-fueled vehicles will be popularized in the heavy goods vehicle and long-haul vehicle fields, such as in the running of trucks and buses. Gas-fueled vehicles are much cleaner and more environmental friendly than petroleum-fueled vehicles. At the same time, gas-fueled vehicles have a better range when compared with current electric vehicles and are more suitable for the transportation of heavy loads [8] as well as long-haul operation. The future price ratio of oil to gas will remain at a high level, thereby giving natural gas vehicles cost advantages allowing them to be popularized particularly in heavy goods and long haul vehicle fields.

III. On the basis of local resource conditions, development measures will be made by local governments. There are cost advantages, policy advantages, as well as charging station networks and large groups of user demand in economically developed coastal areas and other cities. In the meantime, there are already new energy auto industry bases in some cities, making it easier to rapidly popularize new energy vehicles. New energy vehicles, represented by electric vehicles, will be pioneered in coastal areas and emphasis will also be placed on the popularization of electric vehicles for some coal-rich provinces, such as Shanxi province. By the end of 2016, all the taxis in Taiyuan City had been replaced with new energy vehicles. Also, for western areas with rich oil and gas resources, selective popularization shall be performed, combining the energy application and industrial base, as well as consumer demands. For example, there are abundant oil and gas resources in Xinjiang. The price of natural gas is cheap and gas-fueled vehicles have already accounted for $30 \%$ of the total amount for the whole autonomous region. In the coming years, local governments will adjust measures according to the local conditions, such as local resources and industrial distribution.

\section{Acknowledgement}

This research was financially supported by the National Science Foundation Grant No. 71503115. 


\section{References}

[1] Information on http://www.mps.gov.cn.

[2] Shuaibing Wang, Haojie Qin, etc. 2016. Development Status and Trend of Domestic Gas-fueled vehicles [J]. Utomobile Technology. Vol. (10):1-3.

[3] Zhongrong Yuan. 2011. Foreground of LNG Urban Bus [J]. Research and Development. Vol. (6):74-76.

[4] Ali Cuba. 2014. Research on Application Technology of Gas-fueled vehicle [D]. Xi'an: Chang'an University.

[5] Information on http://www.caam.org.cn.

[6] China Automotive Technology \& Research Center. 2016. Annual Report on New Energy Vehicle Industry in China 2016 [M]. Beijing: Social Sciences Academic Press.

[7] Baojun Tang, Jiangpeng Liu. 2015. Development Prospect for China's New Energy Automobile Industry [J]. Journal of Beijing Institute of Technology (Social Sciences Edition). Vol.17(2):1-6.

[8] Wenqian Li. 2016. Introduction about Principle of LNG Trucks and Common Arrangement [J]. Automobile Applied Technology. Vol. (8):246-250. 